\title{
On the phylogenetic position of Pseudophilomedinae within Sarsielloidea (Ostracoda, Myodocopida), with a description of one new Harbansus from Ningaloo Reef and redescription of $\boldsymbol{H}$. paucichelatus from Yucatan
}

\author{
Ivana Karanovic • Lorena Orduña-Martínez • \\ Pedro-Luis Ardisson
}

Received: 26 January 2014/Revised: 25 August 2014/ Accepted: 29 September 2014/Published online: 21 October 2014

(c) Springer-Verlag Berlin Heidelberg and AWI 2014

\begin{abstract}
Previous studies have suggested incongruence between current systematics and molecular phylogenies of Sarsielloidea, with a possible polyphyly of the family Philomedidae. Here, we provide molecular phylogenetic analyses based on $18 \mathrm{~S}$ rDNA and $28 \mathrm{~S}$ rDNA. The former includes five new sequences and 12 from the GenBank, and the latter two new and six sequences from the GenBank. We use three methods, maximum likelihood, maximum parsimony, and neighbor joining, and all reconstructed phylogenies support previously suggested polyphyly, indicating a closer relationship of the subfamily Pseudophilomedinae with one subfamily of Sarsiellidae than with the nominotypical subfamily of Philomedidae. Morphological characters that may be key indicators of the phylogenetic relationships between three Sarsielloidea families are discussed. We also describe the 21st representative of the Pseudophilomedinae genus, Harbansus Kornicker, (Smith Contrib Zool 260:75, 1978), Harbansus ningalooi n. sp., from the Ningaloo Reef, Western Australia. This is the first Harbansus reported from the Australian west coast and the second from the Australian coral reef systems. It
\end{abstract}

Communicated by H-D. Franke.

I. Karanovic ( $\square)$

Department of Life Science, Hanyang University,

Seoul 133-791, Korea

e-mail: ivana.karanovic@utas.edu.au

I. Karanovic

South Korea and Institute of Marine and Antarctic Studies,

University of Tasmania, Hobart, TAS 7001, Australia

L. Orduña-Martínez $\cdot$ P.-L. Ardisson

Departamento de Recursos del Mar, Cinvestav. Carretera antigua

a Progreso, km 6. Apdo. Postal 73-Cordemex, 97310 Mérida,

Yucatan, Mexico differs from all other congeners by peculiar claw-like processes on the posterior infold. Most Harbansus species have relatively restricted distributions, except Harbansus paucichelatus (Kornicker, in Inst Mar Sci 5:195-300, 1958), which has also been postulated to represent a species complex. We present a detailed morphological redescription of this species, based on the freshly collected material from the Yucatan Peninsula, as well as four mitochondrial COI sequences. These become the first COI sequences of the entire superfamily Sarsielloidea available on the GenBank. To facilitate future identification, we include a key to species of Harbansus.

Keywords 18S $\cdot 28 \mathrm{~S} \cdot$ Australia $\cdot$ COI $\cdot$ Mexico Philomedidae $\cdot$ Polyphyly

\section{Introduction}

The superfamily Sarsielloidea contains three families: Philomedidae, Rutidermatidae, and Sarsiellidae. Recent molecular studies (Oakley 2005; Oakley and Cunningham 2002; Oakley et al. 2012) show that the phylogenetic relationships between the three Sarsielloidea families are not resolved, because some Sarsiellidae cluster with some Philomedidae, while other Philomedidae cluster with Rutidermatidae. However, these authors did not discuss morphological characters that may support these phylogenies, but instead call for better taxon sampling.

The family Philomedidae is divided in two subfamilies, Philomedinae and Pseudophilomedinae. Philomedinae contains eight genera: Anarthron Kornicker, 1975; Euphilomedes Poulsen, 1962; Igene Kornicker, 1975; Paraphilomedes Poulsen, 1962; Philomedes Ljiljborg, 1853; Pleoschisma Poulsen, 1962; Scleroconcha Skogsberg, 
1920; and Zeugophilomedes Kornicker, 1986. Pseudophilomedinae has six genera: Angulorostrum Kornicker, 1981; Harbansus Kornicker, 1978; Paramekodon Brady and Norman, 1896; Pseudophilomedes Müller, 1893; Streptoleberis Brady, 1890; and Tetragonodon Brady and Norman, 1896. Streptoleberis is very similar to Harbansus, and Kornicker (1978) even speculated that they may be synonyms. Unfortunately none of the species have been newly reported, and this question remains unresolved. The two initial synapomorphies of Pseudophilomedinae (characteristic saber-like tooth on one of the basal endites of the fifth limb and a small terminal segment on the endopod of maxillula) were discarded by Kornicker (1978) who proposed several new synapomorphic characters but noticed that all of them are homoplastic on some other systematic level, and some even within the sister subfamily Philomedinae.

Harbansus Kornicker, 1978 is a widely distributed marine genus, recorded from all world oceans, with the exception of the Southern and Northern Oceans, and at depths ranging from 1 to 1,015 m (Kornicker 1978, 1992). At the moment, it contains 20 described species, and two in the open nomenclature (Kornicker 1978). Its most widely distributed representative, Harbansus paucichelatus (Kornicker 1958) was collected during a study of ostracods from the Yucatan Peninsula, and here, we use this material and some Philomedidae collected recently from the Sea of Japan to amplify $18 \mathrm{~S}$ rDNA and $28 \mathrm{~S}$ rDNA regions and further test the relationships within Sarsielloidea. We also amplified the mitochondrial COI sequence of $\mathrm{H}$. paucichelatus, and these became the first such sequences for the entire superfamily Sarsielloidea. In fact, at the moment, the GenBank contains only four Myodocopida COI sequences (one unidentified Myodocopida and three of the family Cypridinidae), while the other 50 belong to Halocyprida.

Coral reefs around the world are critically endangered ecosystems. A recent global initiative named CReef (Census of Coral Reef Ecosystems) led by several world institutions from 2004 to 2010, significantly increased global knowledge of reefs' biodiversity. Ningaloo Reef is located on the west coast of Western Australia. The reef is $260 \mathrm{~km}$ long and is Australia's largest fringing coral reef and the only large reef positioned very close to a landmass. In 2011, the reef became a world heritage site, listed by the United Nations. Ningaloo Reef lies within a region identified as a marine biodiversity hotspot and is considered to be one of the 18 richest multi-taxon centers of endemism vulnerable to extinction worldwide (Roberts et al. 2002, Heyward et al. 2010). One new Harbansus species that was collected during a survey of Ningaloo Reef in Western Australia is described here. Myodocopid ostracods from the Ningaloo Reef are poorly known, and so far only two Sarsiellidae have been described (Karanovic 2012). The
Great Barrier Reef in Queensland, which is Australia's and world's largest reef structure, is only slightly better studied, and the myodocopid fauna is mostly represented by Sarsiellidae, while only four Rutidermatidae and one species of Philomedidae (Harbansus slatteryi Kornicker, 1983) are described so far (Kornicker 1982, 1983, 1996).

\section{Materials and methods}

\section{Collecting methods}

Shallow coral reef habitats, from where the samples were taken, can be broadly divided into two zones: inter-tidal reef flat and sub-tidal outer reef to about $30 \mathrm{~m}$. Both zones are sampled by taking dead coral substrate (including fossil or compacted reef, eroded and dead coral heads; coral rubble is particularly productive) in a $20-25-\mathrm{L}$ plastic bucket. These samples were broken up in the laboratory, and the water was washed with alcohol (laced with 5-10 drops of concentrated formaldehyde solution if no subsequent DNA extraction was carried out) and left to stand for 5-30 min. Small samples were collected in 25- or $350-\mu \mathrm{L}$ mesh bags and processed into a bucket the same way. The sample was then rinsed using a seawater hose with the washings passed through a wet sieve or fine-mesh net and either sorted immediately under a microscope or fixed in ethanol (or formaldehyde solution) for later sorting. Sampling on the Ningaloo Reef was carried out under the GBRMPA permit G08-27858.1 and General Fisheries permit (QLD DPI) 95152.

Samples from the Yucatan Peninsula were taken by hydropneumatic suction device for compressed air pulse operated by SCUBA diving, according to Holme and McIntyre (1984) modified as follow: The device consisted of a PVC tube of $127 \mathrm{~cm}$ long and $9 \mathrm{~cm}$ in diameter, where the $20.3 \mathrm{~cm}$ of the lower end of the tube was connected to a diving regulator, which remained attached to a SCUBA tank that supplied compressed air and puts pressure to push the sediment toward the opposite end of the tube which was connected to a bag of $1 \mathrm{~m}$ length with a mesh size of $500-\mu \mathrm{m}$, where the organisms were retained. The sediment (approximately $200 \mathrm{~g}$ ) was poured in sample pots, and the fauna was anesthetized with $15 \% \mathrm{MgCl}_{2}$ and fixed with $98 \%$ alcohol if subsequent DNA extraction was carried or with a solution of $10 \%$ formaldehyde if not. The depth was recorded by HONDEX Portable Depth Sounder. For subjacent water of the sediment, the transparence was taken by Secchi disk, temperature by HOBO H8 Data Logger, salinity by a salinometer, $\mathrm{pH}$ and dissolved oxygen by a digital potentiometer and oximeter, respectively. For sediment, the organic matter was analyzed using the technique proposed by Buchanan (1984) and the grain size by Bale 


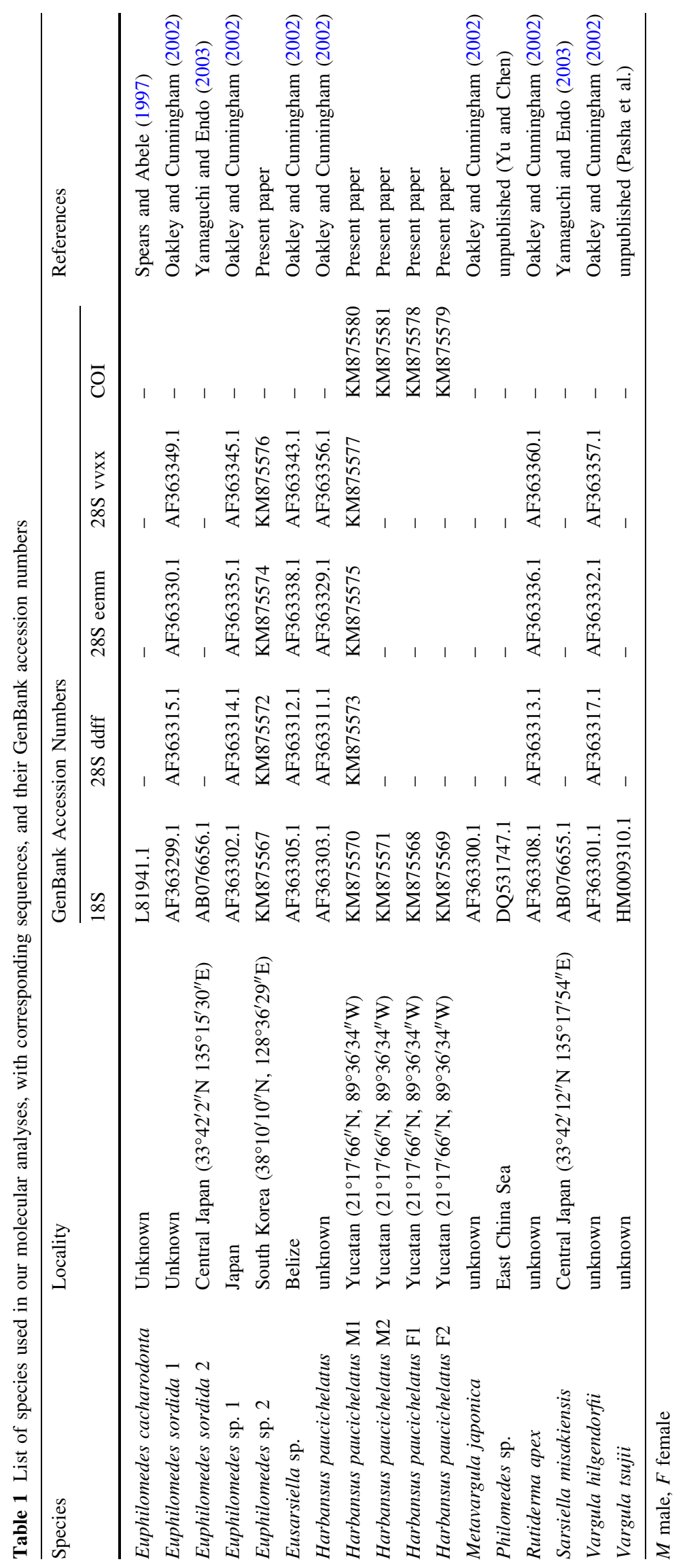


and Kenny (2005). The samples were kept in ice for later analysis in the laboratory, where the samples were sieved through a mesh size of $250-\mu \mathrm{m}$ to separate sediment organisms. Ostracods were picked from the sieved samples under a stereomicroscope Leica Zoom 2000.

\section{Taxonomic methods}

Specimens were dissected and mounted on microscope glass slides in Faure's medium, which was prepared following the procedure of Stock and Von Vaupel Klein (1996). The dissected appendages were then covered with a coverslip, and the valves of each specimen were transferred to a micropalaeontological slide or scanning electron microscope stub. The species were observed under a Leica L2 stereomicroscope and Leica DM 2500 compound microscope with $\mathrm{N}$-plan objectives, and the drawings were made using the drawing tube attachment to the latter microscope. Scanning Electron Micrographs (SEM) were taken with Hitachi S-4700 scanning electron microscope at Eulji University (Seoul) and FESEM JSM-7600F JEOL at Cinvestav in Merida, Yucatan.

In the present paper, the terminology for the most posterior appendage on the body, so-called uropodal lamellae, follows Meisch (2007), while the maxillula and the fifth limb were labeled according to Kornicker (2001, 2002a, b). The material is deposited in the crustacean collection of the Western Australian Museum (WAM) and in the "Colección de Invertebrados Bentónicos de Yucatán" (CYMX).

Abbreviations used in text and figures: A1, antennula; A2, antenna; BO, Bellonci organ; Md, mandibula, Mxl, maxillula; L5, L6, L7, limbs; UL, uropodal lamellae.

\section{PCR amplification methods}

Specimens for molecular analysis were examined under a compound microscope (objective $63 \times$ dry) in propylene glycol for identification to morpho-species with only shell removed. The whole soft body was used for the DNA extraction, except in the case of $H$. paucichelatus M1, from which only one A1 and A2 were used. List of species used in the molecular analysis, gene sequences and the GenBank accession numbers are listed in Table 1. DNA was extracted using LaboPass Tissue Mini extraction kit, following the manufacturer protocol. Fragments of nuclear $18 \mathrm{~S}$ rDNA (on average 1,800 bp) were amplified using the primer pair F1/R9 from Yamaguchi and Endo (2003), fragments of $28 \mathrm{~S}$ rDNA were amplified using the primer pares dd/ff, ee/mm, and vv/xx from Hills and Dixon (1991), and for mitochondrial COI sequences, we used standard Folmer primers (Folmer et al. 1994). For all gene fragments, the PCR was done in a TaKaRa PCR Thermal Cycler Dice in $25 \mu \mathrm{L}$ volume containing: $5 \mu \mathrm{L}$ of the DNA template, $2.5 \mu \mathrm{L}, 10 \times$ ExTaq Buffer, $0.25 \mu \mathrm{L}$ of TaKaRa Ex Taq $(5 \mathrm{U} / \mu \mathrm{L}), 2 \mu \mathrm{L}$ of dNDTP Mixture ( $2.5 \mathrm{mM}$ each), $1 \mu \mathrm{L}$ each primer, and $13.25 \mu \mathrm{L}$ distilled $\mathrm{H}_{2} \mathrm{O}$. The PCR protocol for $18 \mathrm{~S}$ consisted of $5 \mathrm{~min}$ initial denaturation at $94{ }^{\circ} \mathrm{C}$, followed by 35 cycles consisting of denaturation at $95{ }^{\circ} \mathrm{C}$ for $30 \mathrm{~s}$, annealing at $48{ }^{\circ} \mathrm{C}$ for $30 \mathrm{~s}$, and extension at $72{ }^{\circ} \mathrm{C}$ for $1 \mathrm{~min}$, and the final extension at $72{ }^{\circ} \mathrm{C}$ lasted for $5 \mathrm{~min}$. For all three $28 \mathrm{~S}$ fragments, the settings were almost the same, with the exception that we used 40 cycles (denaturation/annealing/extension) and that annealing was done at $50{ }^{\circ} \mathrm{C}$ for $1 \mathrm{~min}$. The protocol for COI segment consisted of initial denaturation for $5 \mathrm{~min}$ at $94{ }^{\circ} \mathrm{C}, 40$ cycles of denaturation for $1 \mathrm{~min}$ at $94{ }^{\circ} \mathrm{C}$, annealing for 2 min at $46{ }^{\circ} \mathrm{C}$, and extension for $3 \mathrm{~min}$ on $72{ }^{\circ} \mathrm{C}$. Final extension was on $72{ }^{\circ} \mathrm{C}$ for $10 \mathrm{~min}$. The PCR products were electrophoresed on the $1 \%$ agarose gels, and, if DNA was present, the products were purified for sequencing reactions, using the LaboPass PCR Purification Kit following the guidelines provided with the kit. DNA was sequenced on ABI automatic capillary sequencer (Macrogene, Seoul, South Korea) using the same set of primers.

Phylogenetic methods

All obtained sequences were visualized using FinchTV v 1.4 BLAST (Altschul et al. 1990). Analyses of GenBank revealed that the obtained sequences are ostracod in origin and not contaminants. Each sequence was checked for quality and sites with possible low resolution and corrected by comparing forward and reverse strands. Sequences were imported in MEGA 5.2.2 (Tamura et al. 2011), and all further analyses, including the addition of highly homologous sequences from the GenBank, were done using this software. In the analysis of $18 \mathrm{~S}$, we have chosen three outgroup species, Vargula hilgendorfii Müller, 1986, V. tsujii Kornicker and Baker, 1977, and Melavargula japonica Poulsen, 1962, and only the first one in the molecular analysis of $28 \mathrm{~S}$. They belong to the superfamily Cypridinoidea, which has been shown in previous molecular analysis (Oakley 2005; Oakley and Cunningham 2002; Oakley et al. 2012) to be the sister taxon of Sarsielloidea. Sequences for all three outgroup species, and another 30 highly similar sequences, all belonging to the superfamily

Table 2 Average pairwise distances (K-2 model) among mitochondrial COI sequences of four specimens of Harbansus paucichelatus Kornicker, 1958 from Yucatan

Harbansus paucichelatus $\mathrm{F} 1$

Harbansus paucichelatus $\mathrm{F} 2$

Harbansus paucichelatus M1

Harbansus paucichelatus M2

0.02

0.01

0.02

For more details see Table 1 
Table 3 Average pairwise distances (K2 + G model) among 18S rDNA sequences of 14 Sarsielloidea specimens and three outgroup species

\begin{tabular}{|c|c|c|c|c|c|c|c|c|c|c|c|c|c|c|c|c|}
\hline \multicolumn{17}{|l|}{ Euphilomedes sordida 2} \\
\hline Euphilomedes sordida 1 & 0.03 & & & & & & & & & & & & & & & \\
\hline Euphilomedes sp. 1 & 0.03 & 0.00 & & & & & & & & & & & & & & \\
\hline Euphilomedes sp. 2 & 0.02 & 0.00 & 0.00 & & & & & & & & & & & & & \\
\hline Eusarsiella sp. & 0.04 & 0.04 & 0.04 & 0.04 & & & & & & & & & & & & \\
\hline Euphilomedes cacharodonta & 0.03 & 0.02 & 0.02 & 0.02 & 0.04 & & & & & & & & & & & \\
\hline Harbansus paucichelatus F1 & 0.04 & 0.04 & 0.04 & 0.05 & 0.03 & 0.05 & & & & & & & & & & \\
\hline Harbansus paucichelatus & 0.05 & 0.05 & 0.05 & 0.05 & 0.04 & 0.05 & 0.01 & & & & & & & & & \\
\hline Harbansus paucichelatus $\mathrm{F} 2$ & 0.04 & 0.05 & 0.04 & 0.05 & 0.03 & 0.05 & 0.00 & 0.01 & & & & & & & & \\
\hline Harbansus paucichelatus M1 & 0.04 & 0.04 & 0.04 & 0.05 & 0.03 & 0.05 & 0.00 & 0.02 & 0.00 & & & & & & & \\
\hline Harbansus paucichelatus M2 & 0.04 & 0.04 & 0.04 & 0.05 & 0.03 & 0.04 & 0.00 & 0.01 & 0.00 & 0.00 & & & & & & \\
\hline Melavargula japonica & 0.07 & 0.07 & 0.07 & 0.07 & 0.07 & 0.07 & 0.08 & 0.08 & 0.08 & 0.08 & 0.08 & & & & & \\
\hline Philomedes sp. & 0.04 & 0.04 & 0.04 & 0.04 & 0.02 & 0.04 & 0.04 & 0.04 & 0.04 & 0.04 & 0.04 & 0.08 & & & & \\
\hline Rutiderma apex & 0.03 & 0.03 & 0.03 & 0.03 & 0.04 & 0.04 & 0.05 & 0.05 & 0.05 & 0.04 & 0.05 & 0.07 & 0.04 & & & \\
\hline Sarsiella misakiensis & 0.04 & 0.04 & 0.04 & 0.04 & 0.01 & 0.04 & 0.04 & 0.04 & 0.04 & 0.04 & 0.04 & 0.07 & 0.01 & 0.04 & & \\
\hline Vargula hilgendorfii & 0.06 & 0.06 & 0.06 & 0.07 & 0.06 & 0.07 & 0.07 & 0.07 & 0.07 & 0.06 & 0.07 & 0.04 & 0.07 & 0.07 & 0.07 & \\
\hline Vargula tsujii & 0.07 & 0.07 & 0.07 & 0.07 & 0.07 & 0.07 & 0.08 & 0.07 & 0.08 & 0.07 & 0.08 & 0.03 & 0.07 & 0.07 & 0.07 & 0.02 \\
\hline
\end{tabular}

For more details see Table 1

Sarsielloidea, were downloaded from the GenBank. Majority of species were only identified to the genus category, with the exception of E. cacharodonta Smith, 1952, Euphilomedes sordida Müller, 1890, M. japonica Poulsen, 1962, R. apex Kornicker and Harrison-Nelson, 1997, Sarsiella misakiensis Kajijama, 1912 (see Table 1). The $18 \mathrm{~S}$ sequences were approximately $1,800 \mathrm{bp}$, while those of three different regions of $28 \mathrm{~S}$ and COI were about $700 \mathrm{bp}$ long. They were aligned with ClustalW (Thompson et al. 1994) with MEGA default parameters. The $\mathrm{K} 2+\mathrm{G}+\mathrm{I}$ was calculated to be the best nucleotide substitution model for the $18 \mathrm{~S}$ data set, $\mathrm{K} 2+\mathrm{G}$ for the $28 \mathrm{~S}$, and T92 for the COI. In distance calculations the gaps (missing data) were treated with pairwise deletion. The distance matrices are presented in Tables 2, 3, and 4. We performed three analyses: maximum likelihood (ML), neighbor joining (NJ), and maximum parsimony (MP) using MEGA. In all three analyses, the bootstrap values (Felsenstein 1985) were calculated with 1000 replicates. In the ML method, we used partial deletion (95\%), nearestneighbor-interchange (NNI) as the heuristic search method, and the initial tree was created automatically (Default-NJ/ BioNJ), while for MP, the SPR (Subtree-Pruning-Regrafting) was the tree searching method. Three pre-aligned sequences of $28 \mathrm{~S}$ were combined before performing the analysis, while the $18 \mathrm{~S}$ sequence was analyzed independently.
Table 4 Average pairwise distances ( $\mathrm{K} 2+\mathrm{G}$ model) among $28 \mathrm{~S}$ rDNA sequences of seven Sarsielloidea specimens and one outgroup

\begin{tabular}{|c|c|c|c|c|c|c|}
\hline \multicolumn{7}{|l|}{$\begin{array}{l}\text { Euphilomedes } \\
\text { sordida } 1\end{array}$} \\
\hline Euphilomedes sp. 1 & 0.01 & & & & & \\
\hline Euphilomedes sp. 2 & 0.01 & 0.01 & & & & \\
\hline Eusarsiella sp. & 0.10 & 0.10 & 0.11 & & & \\
\hline $\begin{array}{l}\text { Harbansus } \\
\text { paucichelatus }\end{array}$ & 0.11 & 0.11 & 0.11 & 0.09 & & \\
\hline $\begin{array}{l}\text { Harbansus } \\
\quad \text { paucichelatus M1 }\end{array}$ & 0.11 & 0.11 & 0.11 & 0.09 & 0.02 & \\
\hline Rutiderma apex & 0.08 & 0.08 & 0.08 & 0.11 & 0.12 & 0.11 \\
\hline Vargula hilgendorfii & 0.18 & 0.18 & 0.18 & 0.17 & 0.19 & 0.17 \\
\hline
\end{tabular}

For more details see Table 1

\section{Results}

Taxonomic description

Class Ostracoda Latreille, 1802

Subclass Myodocopa Sars, 1866

Order Myodocopida Sars, 1866

Suborder Myodocopina Sars, 1866

Family Phylomedidae Müller, 1906

Subfamily Pseudophilomedinae Kornicker, 1967

Genus Harbansus Kornicker, 1978

Harbansus ningalooi n. sp. (Figs. 1, 2, 3, 4, 5) 
Fig. 1 Harbansus ningalooi $\mathrm{n}$. sp. SEM, Holotype: a RV, lateral view from the outside; b branching surface seta; c detail of the surface showing non-branching setae; $\mathbf{d}$ details of the fossae structure; e pores around fossae
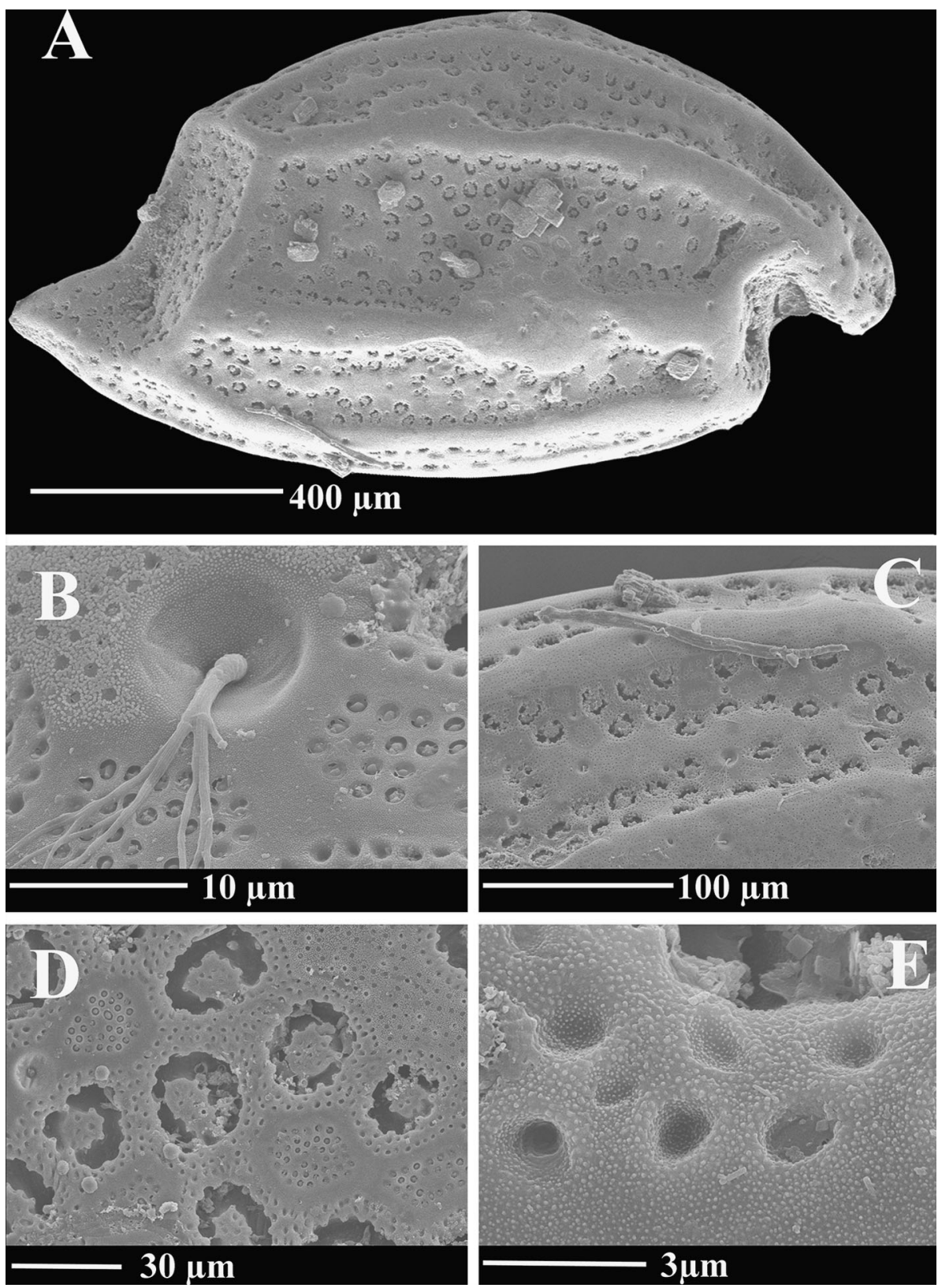

Type material

Holotype (Female), dissected on one slide, valves on SEM stub (WAM C57053); 2 paratypes (subadult females) kept in $70 \%$ ethyl alcohol (WAM C57054).

Type locality

Western Australia, Ningaloo Reef, AU VI, 1489, ARMS-1, $17 / 05 / 2010$, rock, $d=13 \mathrm{~m}, \quad$ CReef, $22^{\circ} 46^{\prime} 8.832^{\prime \prime} \mathrm{S}$ $113^{\circ} 42^{\prime} 16.488^{\prime \prime} \mathrm{E}$.

\section{Diagnosis}

Surface with shallow pits, two dorsal and two ventral longitudinal ridges, one anterior and one posterior. Beside large shallow pith, smaller pores also present. Shell elliptical with prominent pointed caudal process. Clear bulge present antero-ventrally. Antero-ventral infold striate. Posterior infold with several thick setae and claw-like extensions.

Description of adult female

Carapace sub-rectangular with prominent rostrum, and projecting (relatively pointed) caudal process. Dorsal 
Fig. 2 Harbansus ningalooi $\mathrm{n}$. sp. SEM, Holotype: a LV, lateral view from inside; b details of the antero-ventral infold; $\mathbf{c}$ anterior infold showing setae; d posterior infold showing claw-like structures; e detail of the postero-ventral margin; $\mathbf{f}$ setae on the posterior infold; $\mathbf{g}$ detail of the largest claw on the posterior infold; $\mathbf{h}$ detail of setae on the posterior infold; $\mathbf{i}$ setae on the ventral margin


$40 \mu \mathrm{m}$
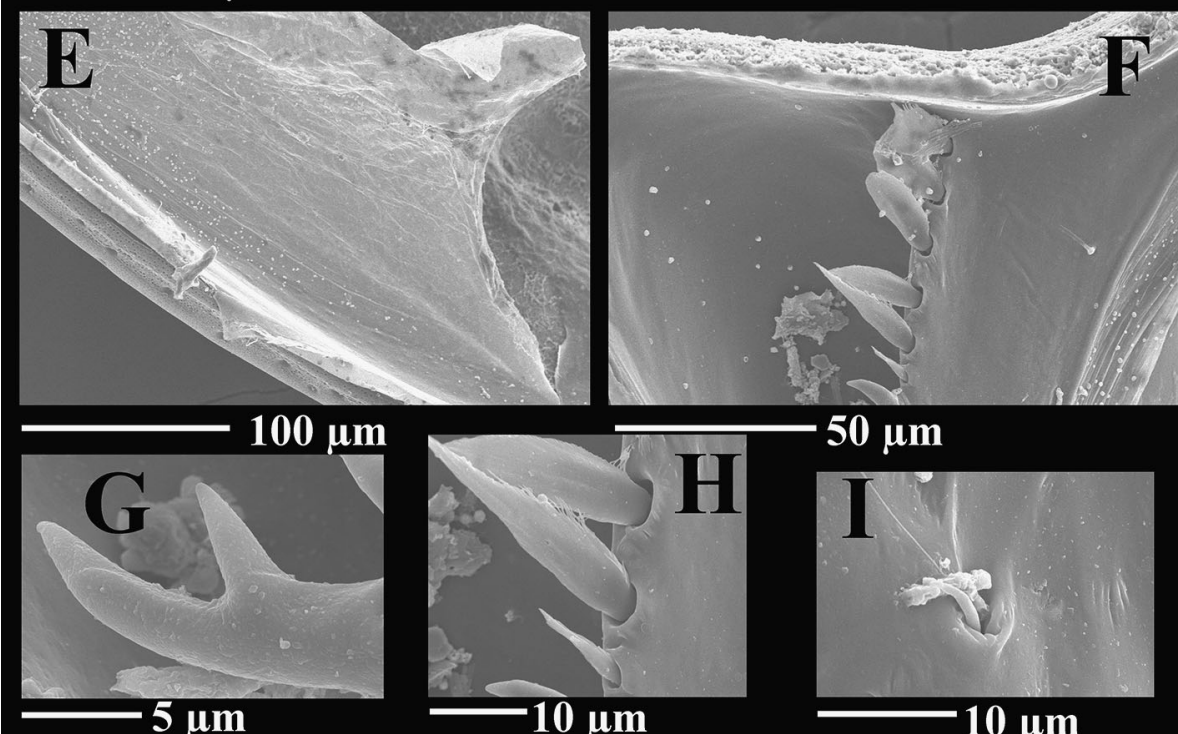

$\mathbf{5 0} \mu \mathrm{m}$

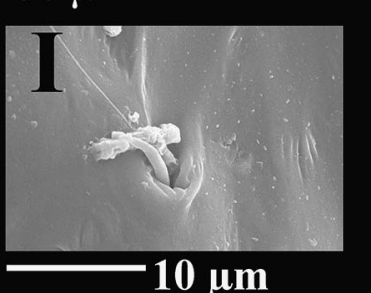

margin almost evenly rounded, with the greatest high before middle $\mathrm{L}$, and gently sloping towards posterior end. Ventral margin rounded (Figs. 1a, 2a). Surface of carapace with four longitudinal ridges: two running dorsally and two ventrally. Two vertical ridges also present: one running posteriorly, other anteriorly; vertical ridges connecting horizontal ones. Surface covered with large, shallow pits (Fig. 1c, d), in between which numerous small pores also present (Fig. 1d, e). Some surface setae branched and long (Fig. 1b), some short and not branched. Two clear rounded bulging structures present: one situated antero-ventrally (Fig. 2b), other on rostrum (Fig. 2c). These bulging structures best observed from the inside, lateral view (Fig. 1a). Selvage very narrow all around carapace (Fig. 2e). Rostral infold with five setae (Fig. 2c), anteroventral infold with seven ribs (striation). Posterior infold with six short and broad papappose setae situated dorsally (Fig. 2f, h), and eight claw-like structures: dorsal most and ventral most claws being largest, and ventral most additionally forked distally (Fig. 2d, g). Several short setae also present along posterior and ventral infold (Fig. 2i). Carapace $1.4 \mathrm{~mm}$ long.

A1 (Fig. 3b, c). First segment bare. Second segment with one serrulate dorsal seta situated bellow middle L of 
Fig. 3 Harbansus ningalooi $\mathrm{n}$. sp. Holotype: a $\mathrm{Md}(1,2,3-$ three segments of the endopod); b distal segments of A1; c proximal segments on A1 with Bellonci organ and medial eye; d L7. Scale $0.1 \mathrm{~mm}$

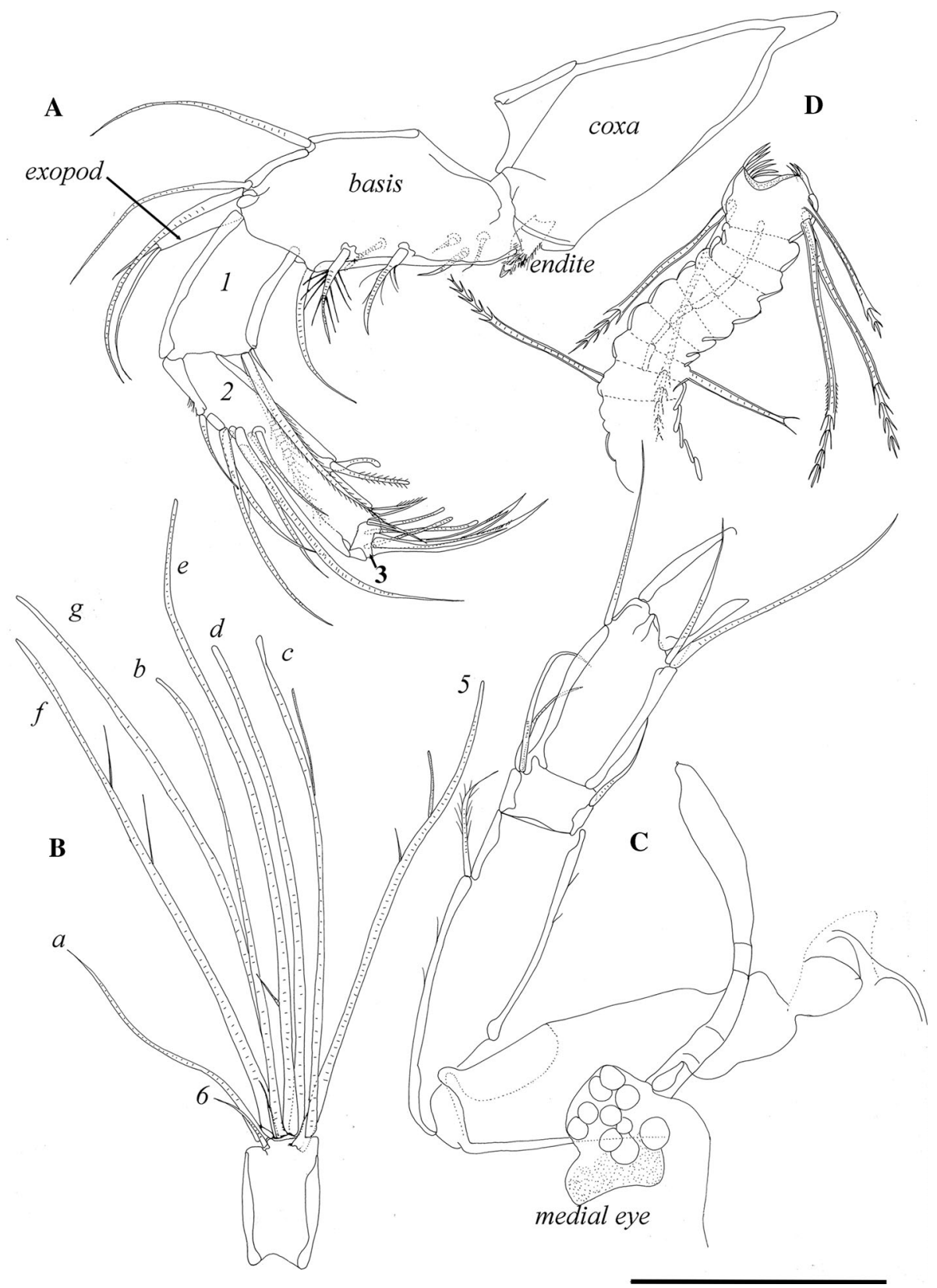

segment and exceeding distal margin of the following segment. Third segment short and with one ventral annulated, bare seta; and two dorsal bare setae; none of these setae exceeds distal end of the fourth segment. Fourth segment with one dorsal, bare and annulated seta exceeding distal end of the seventh segment. Same segment with two ventral annulated bare setae, one longer than other. Ventral seta of the fifth segment with two distal marginal filaments. Sixth segment fused with the fifth and with very short medial bare seta. Seventh segment with a-seta much longer than seta on the sixth segment; c-seta with one long filament; b- and d-setae subequally long and about same $\mathrm{L}$ as seta on the fifth segment. Eight segment with setae g- and e- (g-seta bare, e-seta with one filament) almost subequally long, f-seta with two filaments. One very short additional seta present (most probably) on the eight segment.

Lateral eyes absent, medial eye (Fig. 3c) present and pigmented, with about 10 ommatidia. Bellonci organ with five septae, distally with very small tip.

A2 (Fig. 4a). Protopod without any seta. Endopod 3-segmented: first segment basally with two short setae, second segment with one long sub-distal seta, and third segment with pointed tip but without any seta. Exopod 9-segmented. First segment bare; segments from 2 to 8 with one strong, seta with thick spines proximally and thin setulae distally. Ninth segment with two seta, one long, but 
Fig. 4 Harbansus ningalooi $\mathrm{n}$. sp. Holotype: a A2; b L6 (1, 2, 3, 4, 5-endites); c, d UL. Scale $0.1 \mathrm{~mm}$


almost bare seta (except for thin setulae distally), and one shorter bare seta.

Md (Fig. 3a). Coxa endite spinous with distal tip strongly sclerified. Basis with three subequally long, bare and annulated dorsal setae. Ventrally basis with proximal group of three small bare setae, followed by two serrulate longer setae, in between which another small and bare seta situated; one additional longer, bare annulated seta present on the distal margin; this seta longer than any other ventral setae. Exopod 1-segmented and segment not reaching distal margin of the first endopodal segment. Exopod distally with two thin, bare setae, one two times longer than the other. First endopodal segment with three setae ventro-distally: two long, serrulate and annulated setae exceeding distal end of the following segment, and one very short and bare seta. Second segment of endopod dorsally with a total of seven setae, some short, some long, but all bare and annulated; same segment medioventrally with two setae: one serrulate, other bare and with rounded tip; two more spine-like setae present ventro-distally. Terminal segment with two strong (but finely serrated) claws and three fine, bare setae, all with rounded tips.

Mxl (Fig. 5a). Precoxa with five spine-like setae, each with long and stiff setulae. Coxa with one dorsal serrulate seta and two endites with five and six claw-like setae, some 
Fig. 5 Harbansus ningalooi $\mathrm{n}$. sp. Holotype: a Mxl; b square tooth on basis second endite L5 (1 and 2-basis endites); c exopod, and endopodal segments ( 1 and 2$)$ of L5; $\mathbf{d}$ part of basis and some of the setae ( 1 and 2-basis endites). Scale $0.1 \mathrm{~mm}$



serrulate, some plumose. Basis with one annulated, bare dorsal seta and one bare, long ventral seta. Exopod with two setae: longer one bare, shorter serrulate. Endopod first segment with dorsal seta carrying few setulae. Total of 12 setae and/or claws present distally, some belonging to the first and some to the second segment. Exact position of each seta very hard to observe.

L5 (Fig. 5b-d). Basis endite one with bluntly serrated teeth, two medial pappose setae and one short pappose setae distally. Basis endite two consisting of a large tooth with medial spine-like extension. Three coxal endites hard to distinguish between each other, but third one carrying six setae. Exopod with two setae, endopod with two endites: one with seven setae, followed by one claw, and other with six setae.

L6 (Fig. 4b). With one short epipodite seta. First endite with three short and smooth setae; second with two pappose, annulated setae; third endite with six pappose annulated setae; fourth with four pappose annulated setae; end segment with three distal annulated pappose setae and one longer seta (also pappose and annulated).

L7 (Fig. 3d). Two setae in proximal group, one on each side and six setae in distal group (three on each side). Six curved teeth present on the comb, and three on the peg side.

UL (Fig. 4c, d). Each lamella with six claws followed by small posterior extension. Claws 1, 2, and 4 primary; claw 3, 5 , and 6 secondary. Only the first claw with strong teeth on posterior margin, other claws with weaker teeth, and secondary claws with very fine serration.

Males: Not known.

Etymology: The species is named after the type locality.

Remarks and affinities

Harbansus ningalooi stands apart from other congeners by the presence of peculiar teeth-like structures on the posterior infold and only one (instead of two) long seta on the posterior extension of the L6. It belongs to the group of species with longitudinal ridges on the carapace, together with H. bradmyersi Kornicker, 1978; H. ferox Kornicker, 1992; H. flax Kornicker, 1998; H. magnus Kornicker, 1984; H. paucichelatus, H. slatteryi Kornicker, 1983; H. thrix Kornicker, 1992; H. vatrax Kornicker, 1995; H. vix Kornicker, 1991; and H. vortex Kornicker, 1995. Harbansus ningalooi is morphologically most similar to $H$. slatteryi, described from the Lizard Island, Queensland (Kornicker 1983). The two species have a very similar shape and ornamentation of carapace, and they both have two long claws on the terminal segment of the Md endopod. The new species and $H$. magnus are the only two in this group that have seven dorsal bristles on the second endopodal segment of Md. However, H. magnus is the largest species in the genus (more than $2 \mathrm{~mm}$ long) and has more than six claws on the UL. All other species clearly differ from $H$. 
Fig. 6 Harbansus

paucichelatus (Kornicker, 1958)

SEM, female: a RV, lateral

view from the outside; $\mathbf{b}$ fossae; c details of fossae; $\mathbf{d}$ small nodules inside fossae; e seta on the surface; $\mathbf{f}$ nodules inside fossae and pores on the edges. Scale $0.1 \mathrm{~mm}$
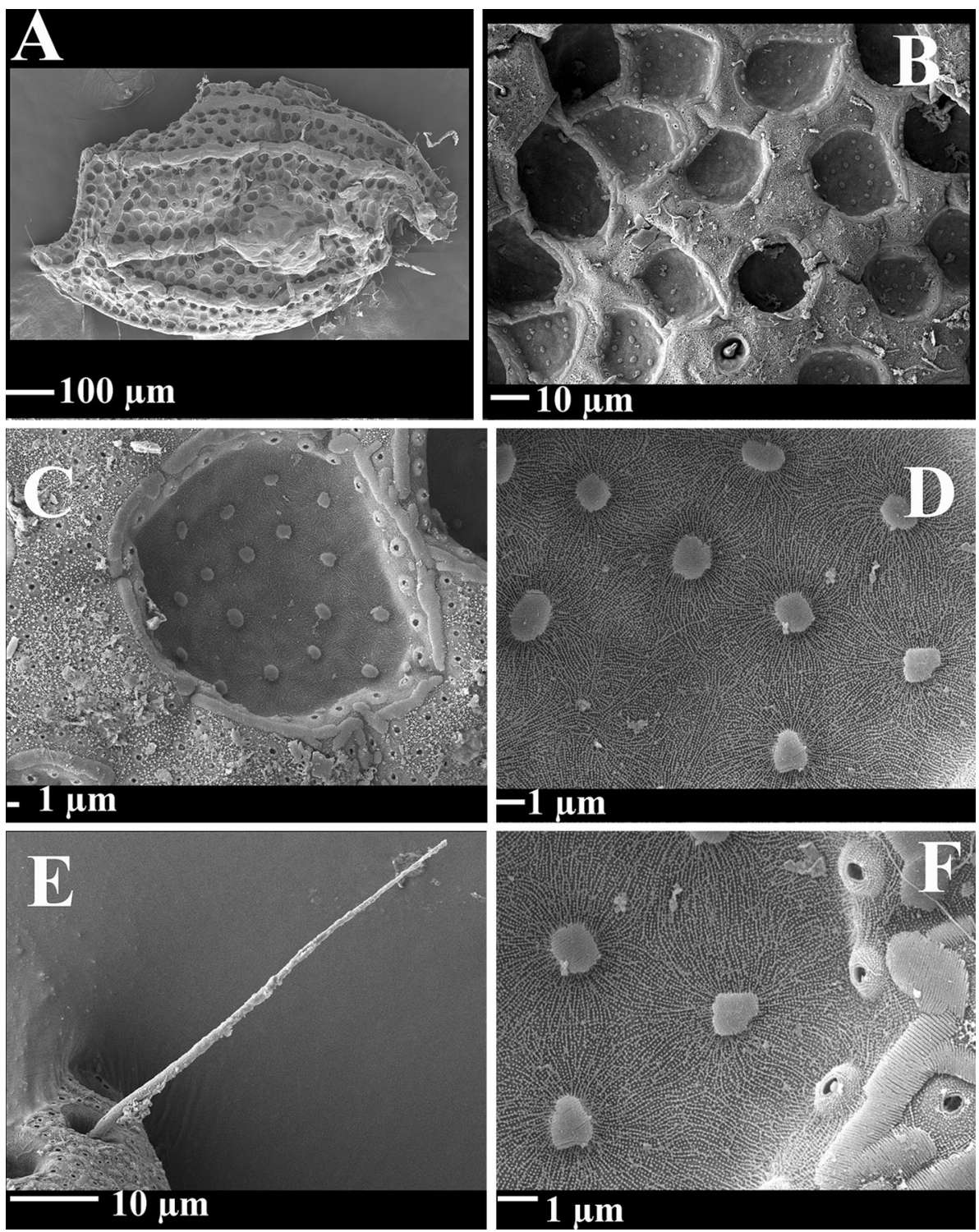

ningalooi by the carapace shape, chaetotaxy of the $\mathrm{Md}$, and other details of their morphology.

The adult females of the new species have swimming bristles on the A2 exopod which, according to Kornicker (1978), means that they are swimmers, not crawlers. We have not found males, and the presence of the lateral eyes in this sex is therefore not certain. As for the females, it seems that they only have the medial eye.

Harbansus paucichelatus (Kornicker, 1958) (Figs. 6, 7, $8,9)$.

Synonymy

Philomedes paucichelata new species-Kornicker, 1958: p. 233, Figs. 46, 4A-B, 54, A-E, 55, A-C, 87, B, E, H.
Harbansus paucichelatus Kornicker, 1958 n. comb.Kornicker, 1978: p. 16, Figs. 5, 6, 7, 8, 9, plates 1, 2.

Harbansus paucichelatus Kornicker, 1958-Kornicker, 1984: p. 59, Figs. 32-37; Kornicker et al., 2002: p. 35, Figs. 23-31; Kornicker et al. 2007b: p. 87.

Material examined

1. Three female dissected on three slides and one male dissected on one from: Mexico, Yucatan Peninsula, Between Chabihau and Santa Clara, $21^{\circ} 22^{\prime} 4.33^{\prime \prime} \mathrm{N}$, $89^{\circ} 04^{\prime} 13.66^{\prime \prime} \mathrm{W}, 08 / 05 / 2005, d=1.4 \mathrm{~m}$, transparence $($ water $)=0.9 \mathrm{~m}, T$ (water $)=29.8{ }^{\circ} \mathrm{C}$, salinity $=41$, $\mathrm{pH}=7.96, \quad$ Dissolved $\quad$ oxygen $=7.59 \mathrm{mg} \mathrm{L}^{-1}$, organic matter $=1.15 \%$, grain size $($ sediment $)=1.6$ $\varnothing$. One female mounted on SEM stub from: Mexico, 
Fig. 7 Harbansus

paucichelatus (Kornicker, 1958)

SEM, female: a LV, lateral view from the inside; $\mathbf{b}$ detail of the posterior infold setae; $\mathbf{c}$ detail of the rostral infold; $\mathbf{d}$ soft body; e Md; f UL. Scales $0.1 \mathrm{~mm}$


Yucatan Peninsula, Between Chabihau and Santa Clara, $21^{\circ} 22^{\prime} 06.28^{\prime \prime} \mathrm{N}, 89^{\circ} 04^{\prime} 14.59^{\prime \prime} \mathrm{W}, 08 / 05 / 2005$, $d=1.1 \mathrm{~m}$, transparence $($ water $)=0.7 \mathrm{~m}, T$ (water) $=$ $21.8^{\circ} \mathrm{C}$, salinity $=30, \mathrm{pH}=7.74$, dissolved oxygen $=5.8 \mathrm{mg} \mathrm{L}^{-1}$, organic matter $=0.46 \%$, grain size $($ sediment $)=1.2 \varnothing$. 47. Specimens are kept in alcohol (CYMX-1601).

2. One male dissected on one slide, shell on micropaleontological slide and one antenna and antennula used for DNA extraction (WAM C57055), soft parts of one male and two females used for DNA extraction, their shell kept on micropaleontological slides (in the first author collection) from: Mexico, Yucatan Peninsula, Between Progreso and Telchac, $21^{\circ} 17^{\prime} 66^{\prime \prime} \mathrm{N}$, $89^{\circ} 36^{\prime} 34^{\prime \prime} \mathrm{W}, 29 / 11 / 2013$.

\section{Diagnosis}

Surface with deep ridges: two dorsal and two ventral longitudinal, one anterior, and one posterior ridge. Beside large pits, smaller pores also present. Shell sub rectangular, with prominent, pointed caudal process. Posterior infold with several thick setae.

Description of adult female

Carapace sub-rectangular with prominent rostrum and relatively pointed caudal process. Dorsal margin almost evenly rounded, with greatest high around middle $\mathrm{L}$, and gently sloping towards posterior and anterior ends. Ventral margin rounded (Figs. 6a, 7a, 8a). Surface of carapace with 
Fig. 8 Harbansus

paucichelatus (Kornicker, 1958)

$a, b, e$, female, slide $2 ; c, d$,

female, slide 1: a RV, lateral

view from the outside; $\mathbf{b} \mathrm{A} 1$;

c UL; d Md (1, 2, 3-endopod

segments); e A2. Scales $0.1 \mathrm{~mm}$

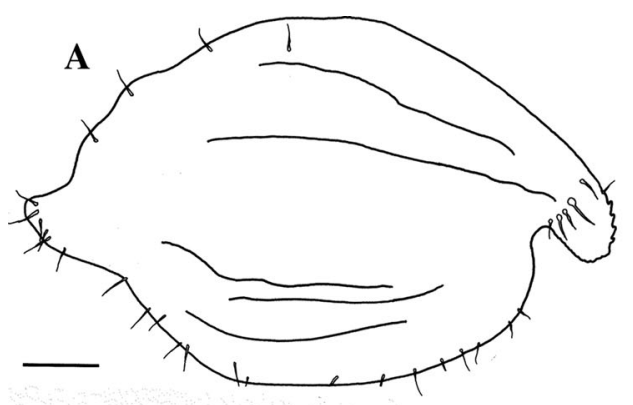

B


four longitudinal ridges: two running dorsally and two ventrally. Two vertical ridges also present one running posteriorly, other anteriorly; vertical ridges connecting horizontal ones. Surface covered with large, deep pits (Fig. 6b), in between which numerous small pores also present, as well as around rims of large pits. Inside these pits peculiar structure consisting of nodules connected with radial networks of small, linearly distributed small dots (Fig. 6c, d, f). Some surface setae not branched (Fig. 6e). Selvage relatively narrow all around carapace (Fig. 7a-c) and with fringe of setulae. Rostral infold with five setae, rostrum also marginally serrated. Posterior infold with five short and broad pappose setae situated dorsally (Fig. 7b). Carapace approximately $0.8 \mathrm{~mm}$ long.

A1 (Fig. 8b). First segment bare. Second segment with one serrulate dorsal seta situated below middle L of segment and not reaching distal margin of same segment. Third segment short and with one ventral annulated, bare seta; and two dorsal bare setae; none of these setae exceeds distal end of fourth segment. Fourth segment with one dorsal, bare and annulated seta exceeding distal end of fifth segment. Same segment with two ventral annulated bare setae, one longer than other. Ventral seta of fifth segment with one distal marginal filament. Sixth segment fused with 
Fig. 9 Harbansus paucichelatus (Kornicker, 1958). a Female, slide 1; b female slide 3 ; c-f male: a L 7; b L6 (1, 2, 3, 4, 5-endites); c $\mathrm{UL}$; d hemipenis; e endopod A2; f A1. Scales $0.1 \mathrm{~mm}$


B

C

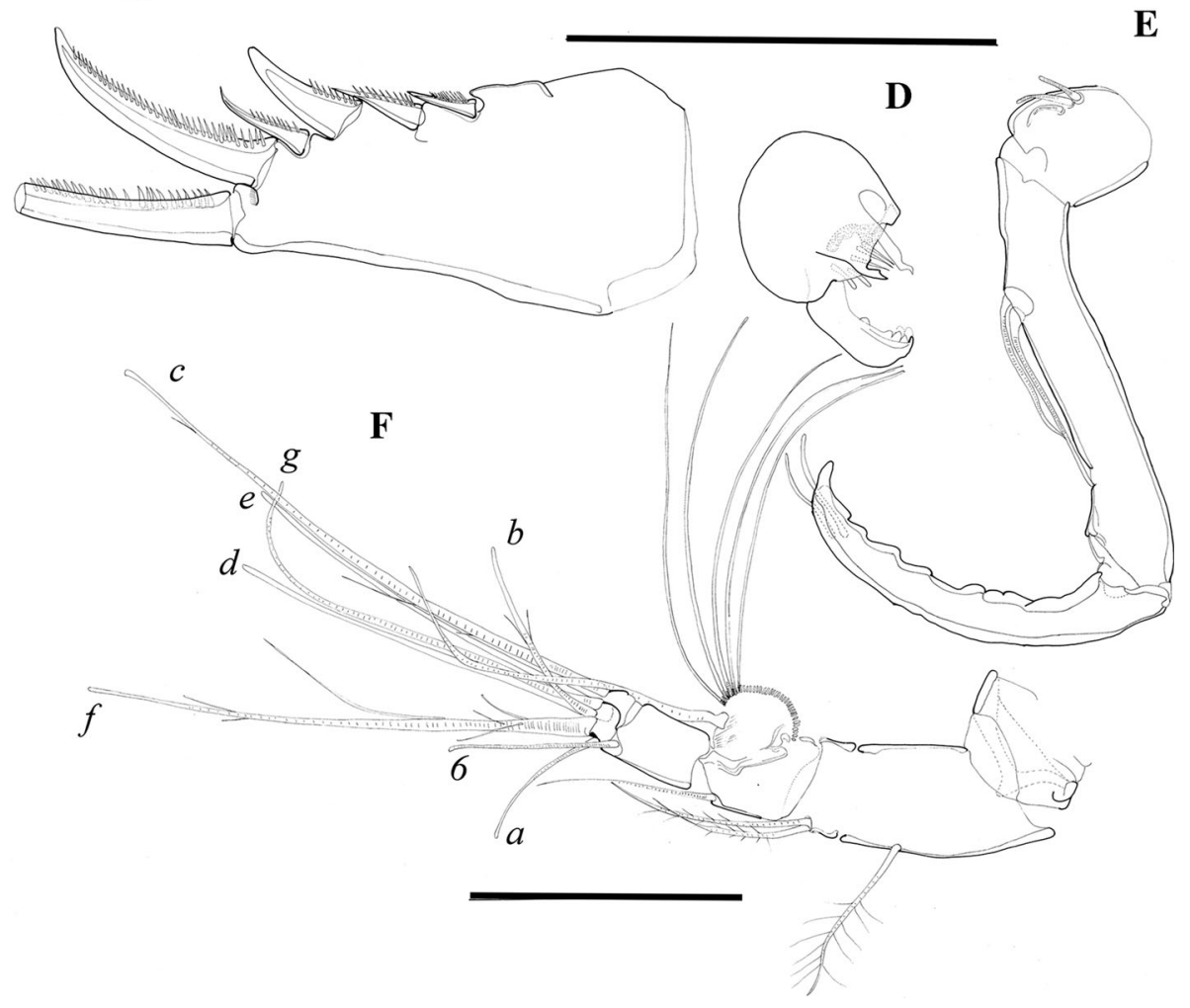

fifth and with bare seta. Seventh segment with a-seta much shorter than seta on sixth segment. b- and d-seta subequally long and without filaments; c-seta three filaments; e-seta bare, g-seta slightly shorter and with one filament, f-seta with one filament. Lateral eyes absent, medial eye small and pigmented.

A2 (Fig. 8e). Protopod without any seta. Endopod 2-segmented: first segment basally with two short setae, second segment with one long sub-distal seta, this segment with rounded tip. Exopod 9-segmented. First segment bare; segments from 2 to 8 with one strong seta with thick spines proximally and thin setulae distally. Ninth segment with two seta, one long, and similar to other setae, and one shorter bare seta.

Md (Figs. 7e, 8d). Basis with three subequally long, bare and annulated dorsal setae. Ventrally basis with two short pappose setae. Exopod 1-segmented and segment not reaching distal margin of first endopodal segment. Exopod distally with two thin, bare setae, one about five times longer than the other. First endopodal segment with three setae ventro-distally: one long, pappose and annulated setae exceeding distal end of following segment, and two 
short and bare seta. Second segment of endopod dorsally with total of four setae; same segment ventro-distally with four short bare setae. Terminal segment with three claws and three fine, bare setae.

L6 (Fig. 9b). First endite with three setae: two short pappose and one longer seta; second with three pappose, annulated setae; third endite with five pappose annulated setae; fourth with five pappose annulated setae, end segment with three distal annulated pappose setae and three longer seta (also pappose and annulated).

L7 (Fig. 9a). Two setae in proximal group, one on each side and four setae in distal group (two on each side). Three curved teeth present on the comb, and three on the peg side. Each seta with four bells at the tip.

UL (Figs. 7f, 8c). Each lamella with six claws followed. Claws 1, 2, and 4 primary; claw 3, 5, and 6 secondary. All primarily claws strongly serrated.

Description of adult male

A1 (Fig. 9f). Second segment with one pappose dorsal seta. Third segment short with two pappose dorsal setae, no ventral setae. Fourth segment with one dorsal seta, no ventral setae. Fifth segment wedged ventrally between the fourth and the sixth segments; sensory seta with bulbous proximal part with abundant filaments, and stem with three filaments near middle and two spines at tip. Sixth segment medial seta with short. Seventh segment: a-seta same L as seta on the sixth segment; b-seta one-third longer than a-bristle, with 2 distal filaments; c-seta longer than sensory seta on the fifth segment. Eight segment: d- and e-setae shorter than c-bristle, bare with blunt tips, f-seta as long c-seta, with marginal filaments; g-bristle shorter than c-bristle. Both lateral and medial eyes present.

A2 (Fig. 9e). Endopodite 3-segmented, first segment short with three short anterior setae; second segment elongated, with two long proximal setae; third segment elongated, reflexed, with two short setae near sclerotized beak-like tip.

Hemipenis (Fig. 9d). With rounded basal part carrying five seta-like structures and two hooks. An elongated process attached to the round base, curved distally and with seven teeth.

UL (Fig. 9c). Similar to female, except that the fourth claw being broader.

\section{Remarks}

Harbansus paucichelatus is the most widespread species of the genus. Kornicker (1984) noticed that it is very variable, so that it may represent a species-complex, and he considered the following features to be variable: primary claws on the UL can be stout or slender; shell may have many, few or no spines on the surface; exopod of A2 may bare long or short swimming setulae; tip of A2 endopod in female with or without terminal spine. Although Kornicker (1978) provided SEM photographs of the shell surface, it is impossible to discern on them peculiar structures detected in our specimens, i.e., small nodules within fossae interconnected with radial lines of dots. Our specimens all suffered from decalcification (due to improper sample fixation with non-buffered formaldehyde solution), as well as the ones that Kornicker (1978) illustrated. The Mexican specimens did not have any spines on the surface of the shell; the UL had stout claws; and the female A2 endopod lack terminal spine. We have also found that the average pairwise distances between 18S rDNA sequences of the new material and the one deposited on the GenBank is about $1 \%$, and between $28 \mathrm{~S}$ rDNA sequences $2 \%$, which may also indicate a separate species (see Appendix 1), but this needs further studies as we cannot confirm identification of previously available GenBank sequences. Due to the high similarity in carapace shape and the morphology of other appendages, including A1 and hemipenis of our males and the ones reported by Kornicker (1984), we identified our specimens from Yucatan as $H$. paucichelatus. By providing mitochondrial COI sequence, we open a possibility for future molecular comparisons between our population and other populations of $H$. paucichelatus from its wide area of distribution.

\section{Key to species of Harbansus}

1. Posterior infold with claw-like structures $\ldots H$. ningalooi $\mathrm{n}$. sp.

- Posterior infold without spine-like structures... 2

2. Shell more than $2 \mathrm{~mm}$ long ... H. magnus Kornicker, 1984

- Shell around $1.5 \mathrm{~mm}$ or less ... 3

3. Carapace not ornamented with fossae ... 4

- Carapace ornamented with fossae ... 6

4. Eight to 10 setae on the rostral infold ... H. tenax Kornicker, 1995

- Four or 5 setae on the rostral infold ... 5

5. Five setae dorsally on the second endopod segment Md ... H. ferox Kornicker, 1992

- Two setae dorsally on the second endopod segment Md ... H. vatrax Kornicker, 1995

6. Carapace with longitudinal ribs ... 7

- Carapace without longitudinal ribs ... 14 
7. Distal seta on the second endopod segment A2 absent ... 8

- Distal seta on the second endopod segment A2 present ... 9

8. Five setae dorsally on second endopod segment $\mathrm{Md}$ and 6 setae on third endite L6 ... $H$. slatteryi Kornicker, 1983

- Six setae dorsally on second endopod segment Md and 5 setae on third endite L6 ... $H$. thrix Kornicker, 1992

9. More than six setae on rostral infold and three setae on the basal segment of endopod A2 ... H. vortex Kornicker, 1995

- Less than 6 setae on rostral infold and 2 setae on the basal segment of endopod A2 ... 10

10. Six setae on the rostral infold ... 11

- Five or 4 on the rostral infold ... 12

11. Seven setae on the second endopod segment Md and 7 setae on third endite L6 ... H. schornikovi Kornicker and Caraion, 1977

- Five setae on the second endopod segment Md and 5 setae on third endite L6 ... H. bradmyersi Kornicker, 1978

12. Three setae on each side of $\mathrm{L} 7$ terminus ... H. vix Kornicker, 1991

- Two setae on each side of L7 terminus ... 13

13. Three teeth on the peg side and 1 on the comb side of L7 terminus ... H. flax Kornicker, 1998

- Six spines on peg side and 2-3 on the comb side of L7 terminus ... H. paucichelatus Kornicker, 1958

14. UL with more than 6 claws ... H. hapax Kornicker, 1995

- UL with 6 claws ... 15

15. Terminal segment of endopod A2 without setae or any other small extensions ... 16

- Terminal segment of endopod A2 with seta ... 18

16. Two setae on each side of terminus L7 ... H. felix Kornicker, 1995

- Three setae on each side of terminus L7 ... 17

17. Only one seta on the basal segment of A2 endopod and two setae on endite one L6 ... H. bowenae Kornicker, 1978
- Two setae on the basal segment of A2 endopod and 3 setae on endite one L6 $\ldots H$. dayi Kornicker, 1978

18. Three setae on each side of terminus L7 ... 19

- Two setae on each side of terminus L7 ... 20

19. Three setae on the basal segment of endopod A2 and 7 setae on the second endopod segment $\mathrm{Md} \ldots H$. barnardi Kornicker, 1978

- Two setae on the basal segment of endopod A2 and 8 setae on the second endopod segment $\mathrm{Md}$... H. hox Kornicker, Harrison-Nelson and Coles, 2007.

20. Four setae on the rostral infold ... H. rhabdion Kornicker, 1970

- Eight setae on the rostral infold ... H. mayeri Kornicker, 1978.

\section{Distribution of Harbansus}

Most of the species have been reported only from their type localities, or nearby areas. The only exception is $H$. paucichelatus (Fig. 10) which has been collected from several localities in the Atlantic Ocean, from North Carolina to Belize (Kornicker 1978, 1984, Kornicker et al. 2002), at depths of $15 \mathrm{~cm}$ to $135 \mathrm{~m}$. The present finding is from Mexico (Yucatan Peninsula), at 1.1 and $1.4 \mathrm{~m}$. The new species is so far the only representative of the genus known from the coral reefs on the west coast of Australia, while another species, $H$. satteryi, was described from the Great Barrier Reef, Queensland (Kornicker 1983). The following species have been described from coral reefs around the world: H. hox from French Frigate Shoals (Kornicker et al. 2007a); H. trix and H. ferox from Mayotte coral reef area (Kornicker 1992); H. vix from Enewetak (Kornicker 1991); and H. flax from the Tuléar Reef (Kornicker and Thomassin 1998). The other 14 species are known from continental shelves and slopes, with $H$. rhabdion collected from deepest waters, i.e., 1,015 $\mathrm{m}$ at Peru-Chile trench (Kornicker 1970, 1978).

\section{Molecular results}

Pairwise distances of the COI sequences between four specimens of $H$. paucichelatus from the Yucatan Peninsula varied between 0 and $2 \%$ (Table 2), which is indicative of intraspecific variation when compared to other crustacean groups (Lefébure et al. 2006). Since there are no other COI sequences belonging to this genus, or any species of the family Philomedidae, we did not provide any cladistic tree. 


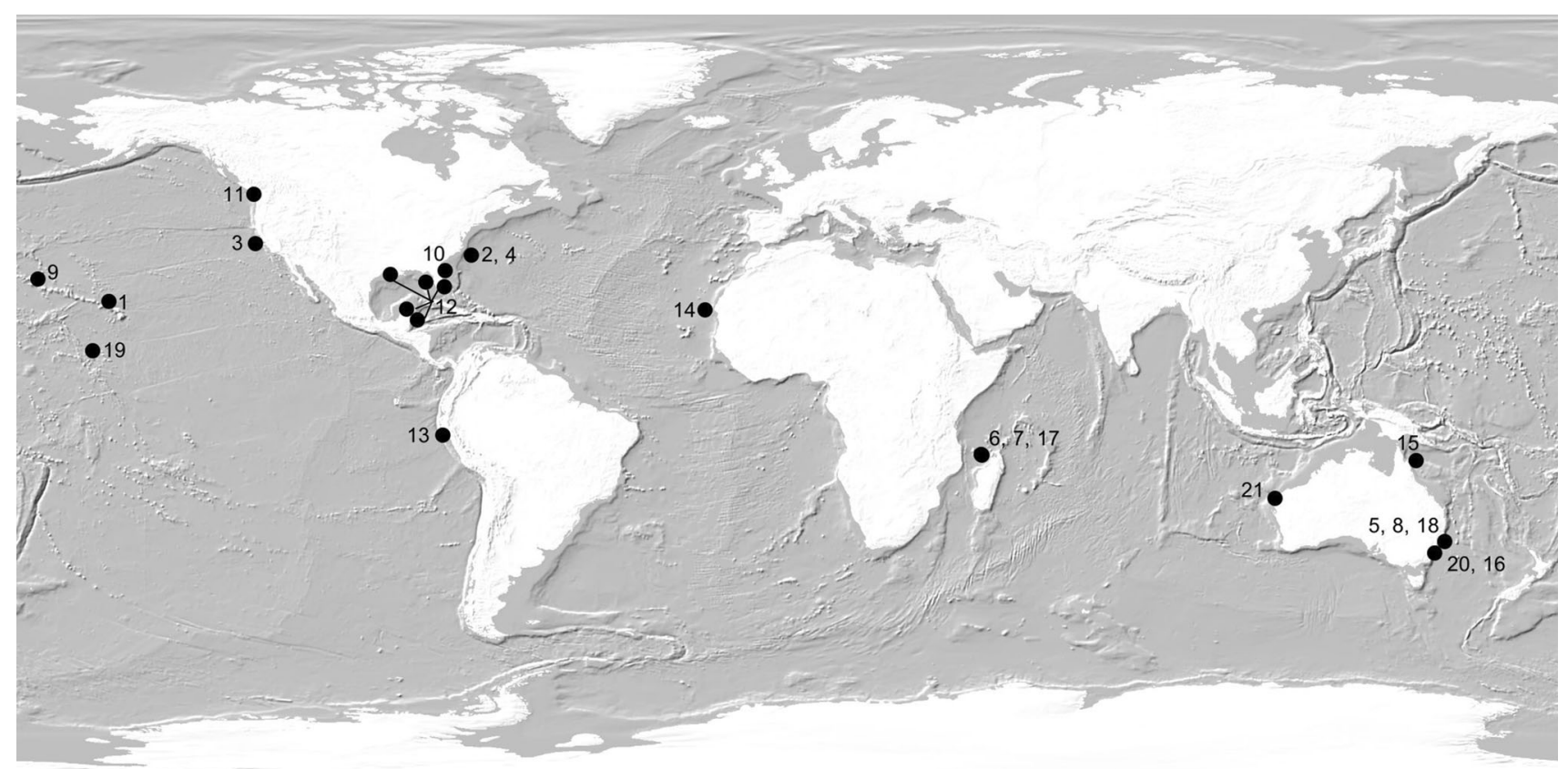

Fig. 10 Map of distribution of Harbansus Kornicker, 1978: $1 \mathrm{H}$. barnardi Kornicker, 1978; 2 H. bowenae Kornicker, 1978; 3 H. bradmyersi Kornicker, 1978; 4 H. dayi Kornicker,1978; 5 H. felix Kornicker, 1995; 6 H. ferox Kornicker, 1992; 7 H. flax Kornicker, 1998; 8 H. hapax Kornicker, 1995; 9 H. hox Kornicker, HarrisonNelson, Coles, 2007; 10 H. magnus Kornicker, 1984; 11 H. mayeri

The aligned sequence data set of $18 \mathrm{~S}$ rDNA contained $1930 \mathrm{bp}$, of which $246 \mathrm{bp}$ was variable, while $172 \mathrm{bp}$ was parsimony informative. Distances between $18 \mathrm{~S}$ rDNA sequences of the 17 studied species varied between 0 and $8 \%$ (Table 3), and those between previously available sequence of $H$. paucichelatus (AF363303.1) and our four specimens of the same species $(H$. paucichelatus F1, F2, M1, M2) was $1 \%$. The lowest pairwise distance was between some species of the genus Euphilomedes and between the Mexican specimens of $H$. paucichelatus. The greatest distance $(8 \%)$ was between the ingroup (Sarsielloidea) and outgroup taxa (Cypridinoidea). The percentage of replicate trees in which the associated taxa clustered together in the bootstrap test (1000 replicates) is shown next to the branches (Fig. 11). The ML, NJ and MP trees did not share the same topology. The NJ supports the position of Rutiderma apex as basal to all other Euphilomedes (bootstrap value $87 \%$ ) and E. sordida 2 as basal to the rest of Euphilomedes (bootstrap value $78 \%$ ). Maximum parsimony places $R$. apex as basal to the entire ingroup, while $E$. sordida 2 represents a basal branch within the ingroup (bootstrap support $71 \%$ ). For the MP tree, bootstrap values for the consensus (50\% cutoff) of seven equally parsimonious trees are shown. The consensus tree had a length of 159 steps, the consistency index 0.786164 , and the retention index 0.841121 .
Kornicker, 1978; $12 \mathrm{H}$. paucichelatus (Kornicker, 1958); $13 \mathrm{H}$. rhabdion (Kornicker, 1970); 14 H. schornikovi (Kornicker and Caraion, 1977); 15 H. slatteryi Kornicker, 1983; 16 H. tenax Kornicker, 1995; $17 \mathrm{H}$. thrix Kornicker, 1992; $18 \mathrm{H}$. vatrax Kornicker, 1995; 19 H. vix Kornicker, 1991; 20 H. vortex Kornicker, 1995; 21 H. ningalooi $\mathrm{n}$. sp

The aligned sequence data set of three 28S rDNA segments $(\mathrm{dd} / \mathrm{ff}$, ee/mm, and $\mathrm{vv} / \mathrm{xx})$ contained $2,356 \mathrm{bp}$, of which 487 bp was variable, while 231 bp was parsimony informative. Distances between $28 \mathrm{~S}$ rDNA sequences of eight species varied between 1 and $18 \%$ (Table 4), and the ones between $H$. paucichelatus from the GenBank (AF363303.1) and one specimen of the same species collected from the Yucatan Peninsula (H. paucichelatus M1) was $2 \%$. The lowest pairwise distance was between species of the genus Euphilomedes, and the greatest between the ingroup (Sarsielloidea) and the outgroup taxon (Cypridinoidea). The percentage of replicate trees in which the associated taxa clustered together in the bootstrap test (1000 replicates) are shown next to the branches (Fig. 12), and the ML, NJ and MP trees shared the same topology. For the MP analysis, single most parsimonious tree had a length of 486 steps, the consistency index of 0.864198 , and the retention index of 0.78 .

\section{Discussion}

With the newly described species, the genus Harbansus contains 21 members. Among the five other genera of the subfamily Pseudophilomedinae, it is most closely related to Angulorostrum, Streptoleberis, and Tetragonodon, as they 
Fig. 11 The ML cladogram based on $18 \mathrm{~S}$ rDNA sequences. Numbers above branches represent bootstrap values for $\mathrm{MP} / \mathrm{NJ} / \mathrm{ML}$. The tree is rooted with the Metavargula-Vargula clade and drown to scale
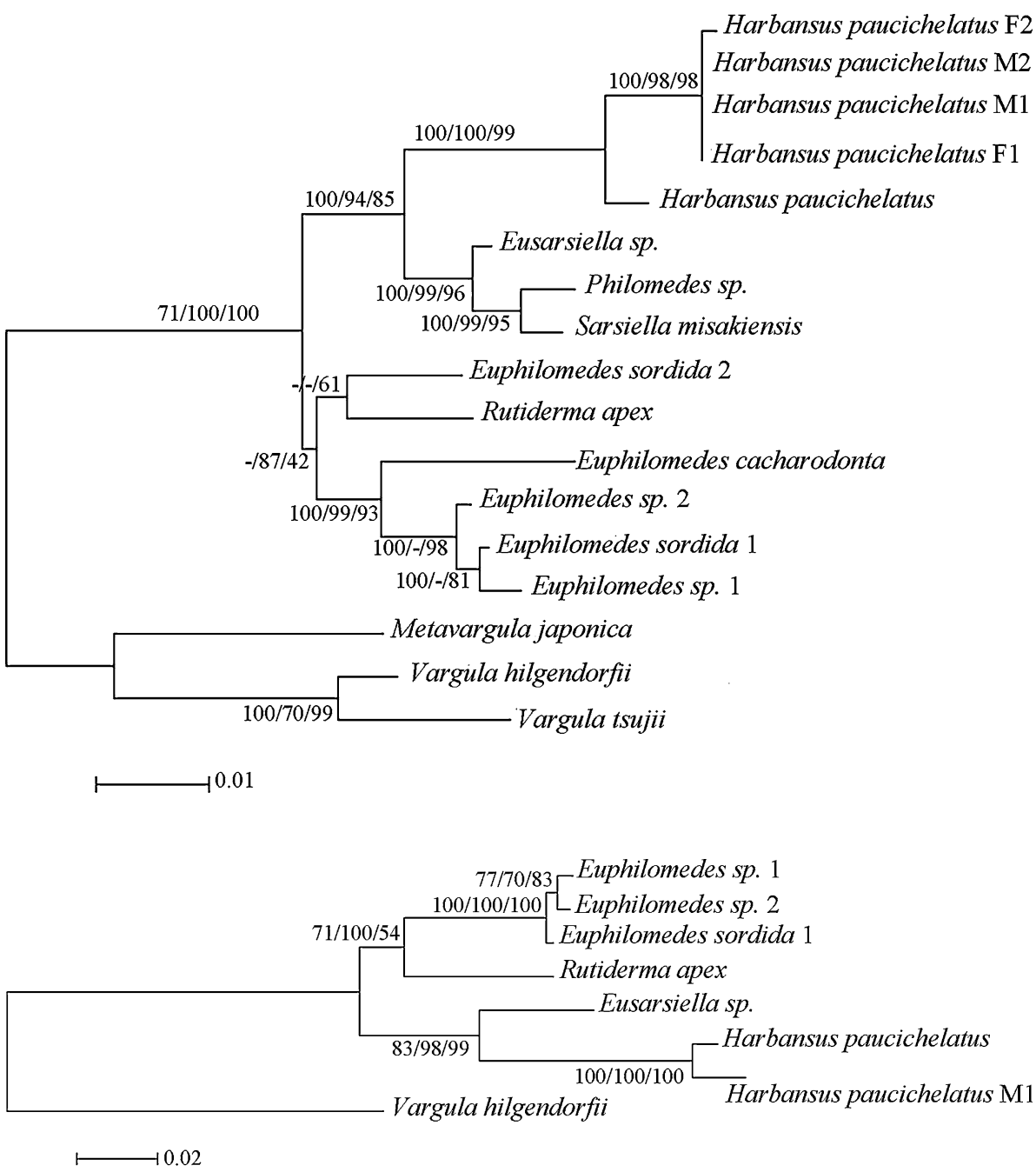

Fig. 12 The ML cladogram based on $28 \mathrm{~S}$ rDNA sequences. Numbers above branches represent bootstrap values for MP/NJ/ML. The tree is rooted with Vargula clade, and drown to scale
Pseudophilomedes, the large tooth is quite different from these four genera, i.e., it does not have a flat distal margin and often has at least slightly elongated anterior end of the basis second endite. On the other hand, characters that clearly separate Pseudophilomedinae from Philomedinae are the presence of peculiar setae on the posterior infold, morphology of the males sensory bristle on the A1, and (partly-see below) not elongated posterior part of the end segment of the L6.

The peculiarly looking setae on the posterior infold with broad base and thickly covered with setulae (see Fig. 2f, h) are not found in any of the Philomedinae genera, but it is common in almost all representatives of the family Sarsiellidae, in particular in the subfamily Dantyinae. Here, we want to point out that the species described here, $H$. ningalooi, has a peculiar claw-like structure ventral to these setae. A relatively similar structure was found in a sarsiellid species, Spinacopia ningalooi Karanovic, 2012, recently described from the Ningaloo Reef (Karanovic 2012). Although Myodocopa ostracods are common on the coral reefs around the world, especially family Sarsiellidae 
(see Karanovic 2012), such peculiar structures have never been reported, and therefore, it would be hard to speculate that this may be an adaptation on coral reefs.

The male sensory bristle on the A1 in Pseudophilomedinae is also common in Sarsiellidae, but not in the subfamily Philomedinae, in which this seta has a more elongated base (see Kornicker 1978) and the setulae are not arranged circularly. Although not mentioned as a diagnostic feature of Philomedinae, we believe that the characteristic appearance of $c$ - and f-setae on the male A1 may be a synapomorphy of this subfamily. Namely, males of this subfamily have these two setae with very strong base and turned upwards (see for example descriptions of several Philomedes species in Kornicker, 1984), while in Pseudophilomedinae they have the same direction as all the other setae on the appendage. A short end joint of the L6 is also common to Sarsiellidae and Rutidermatidae, but it is very rarely found in Philomedinae, such as, for example in the genus Igene (see Kornicker 1978).

The above mentioned morphological characters clearly indicate that Pseudophilomedinae are more closely related to Sarsiellidae than to its supposedly sister subfamily Philomedinae. However, there are numerous important morphological differences even between two members of Sarsiellidae, Dantyinae and Sarsiellinae. The former has a more elongated carapace shape with a prominent rostrum and caudal process (similar to Harbansus and its related genera). Although females of Sarsiellinae are globular, males are elongated. Mandibula of Dantyinae is more similar to Pseudophilomedinae in the distribution of setae and claws, but it is more similar to Sarsiellinae in the segments ratio (see Kornicker and Cohen 1978). All Sarsiellidae have a characteristic morphology of the Mxl endopod with a very short first segment and a typical distribution of claws on the terminal segment, but in Dantyinae, its morphology is somewhere between typical Sarsiellinae and Pseudophilomedinae. Finally, the Sarsiellinae females lack teeth on the L5, while females of Dantyinae have a square tooth similar to Harbansus and its related genera.

The results of our molecular phylogenetic analyses are in accordance with Oakley (2005), Oakley and Cunningham (2002), and Oakley et al. (2012) indicating polyphyly of Philomedidae (Figs. 11, 12). The bootstrap support for the clade Harbansus and Sarsiellidae (Eusarsiella sp. and S. misakiensis) on the $18 \mathrm{~S}$ tree (Fig. 11) is $85 \%$ for ML, $94 \%$ for NJ, and $100 \%$ for MP. The clade consisting of Rutiderma apex (Rutidermatidae) and other Euphilomedes species (Philomedinae) is supported in our ML (although with a very law bootstrap value of $42 \%$ ) and NJ (bootstrap value $87 \%$ ) analyses, but not in our MP analyses. These values are not enough to support close phylogenetic relationship between Philomedinae and Rutidermatidae. The sequence of Philomedes sp. clusters together with two Sarsiellidae and the branch has a high support, but this may be a misidentification, maybe belonging to a male of Sarsiellinae, since they are quite different from females and may easily be confused with Philomedidae. The tree based on 28S sequences (Fig. 12) has also a high support for the Sarsiellidae/Pseudophilomedinae clade, while the Rutidermatidae/Philomedinae clade is not strongly supported on the ML tree (bootstrap value of $54 \%$ ). The molecular results are therefore congruent with morphological data, i.e., that Pseudophilomedinae are more closely related to Sarsiellidae than to Philomedinae. Future systematics of Sarsielloidea could include subfamilies Sarsiellinae, Dantyinae and Pseudophilomedinae, but on the family rank. Both Sarsielloidea and Philomedidae will need revision, but when molecular phylogeny is concerned, it should be tested with representatives of more than one genus of Pseudophilomedinae and Philomedinae, and at least some representatives of Dantyinae.

Acknowledgments The paper was supported by the Australian Biological Resources Study Grant (RF 210-10) to the first author. For the sampling and processing Mexican specimens, further financial support was provided by the "Programa de Ordenamiento Ecológico del Territorio Costero del Estado de Yucatán" project to PLA, the research fund of the "Laboratorio de Bentos, Cinvestav," and a master degree scholarship from the "Consejo Nacional de Ciencia y Tecnología, Mexico," to LOM. We would also like to acknowledge Hanyang University (Seoul) for providing the space and facilities during part of this study. We thank Dr Eugen Kempf for providing information on publications related to Streptoleberis. Second and third authors want to thank Maria Teresa Herrera-Dorantes (Cinvestav, Mexico) for her support in the sampling and sorting of specimens.

\section{References}

Altschul SF, Gish W, Miller W, Myers EW, Lipman DJ (1990) Basic local alignment search tool. J Mol Biol 215:403-410

Bale AJ, Kenny AJ (2005) Sediment analysis and seabed characterization. In: Eleftheriou A, McIntyre A (eds) Methods for the study of marine benthos, 3rd edn. Blackwell, Oxford, pp 43-86

Buchanan JB (1984) Sediment Analysis. In: Holme NA, McIntyre AD (eds) Methods for the study of marine benthos. Blackwell, Oxford, pp 41-65

Felsenstein J (1985) Confidence limits on phylogenies: an approach using the bootstrap. Evolution 39:783-791

Folmer O, Black M, Hoeh W, Lutz R, Vrijenhoek R (1994) DNA primers for amplification of mitochondrial cytochrome $\mathrm{c}$ oxidase I from diverse metazoan invertebrates. Mol Mar Biol Biotechnol 3:294-299

Heyward A, Fromont J, Schönberg CHL, Colquhoun J, Radford B, Gomez O (2010) The sponge gardens of Ningaloo Reef, Western Australia. Open Mar Biol J 4:3-11

Hills DM, Dixon MT (1991) Ribosomal DNA: molecular evolution and phylogenetic inference. Q Rev Biol 66:411-453

Holme NA, McIntyre AD (1984) Methods for the study of marine benthos, 2nd edn. Blackwell, Oxford 
Karanovic I (2012) Two new Sarsiellinae (Ostracoda: Myodocopa) from Ningaloo Reef (Western Australia), with a cladistic analysis of the subfamily and keys to genera. J Nat Hist 46:2285-2327

Kornicker LS (1958) Ecology and taxonomy of recent marine ostracods in the Bimini Area, Great Bahama Bank. Inst Mar Sci 5:195-300

Kornicker LS (1967) The myodocopid ostracod families Philomedidae and Pseudophilomedidae (New Family). Proc US Nat Mus 120:1-21

Kornicker LS (1970) Ostracoda (Myodocopina) from the Peru-Chile Trench and the Antarctic Ocea. Smith Contrib Zool 32:42

Kornicker LS (1978) Harbansus, a new genus of marine Ostracoda, and revision of the Philomedidae (Myodocopina). Smith Contrib Zool 260:75

Kornicker LS (1982) Alternochelata lizardensis, a new species of myodocopine ostracode from the Great Barrier Reef of Australia (Rutidermatidae). Proc Biol Soc Wash 95:793-803

Kornicker LS (1983) Harbansus slatteryi, a new species of myodocopine ostracode from the Great Barrier Reef of Australia (Philomedidae). Proc Biol Soc Wash 96:181-188

Kornicker LS (1984) Philomedidae of the continental shelf of eastern North America and the Northern Gulf of Mexico (Ostracoda: Myodocopina). Smith Contrib Zool 393:78

Kornicker LS (1991) Myodocopid Ostracoda of Enewetak and Bikini Atolls. Smith Contrib Zool 505:140

Kornicker LS (1992) Myodocopid Ostracoda of the Benthédi Expedition, 1977, to the NE Mozambique Channel, Indian Ocean. Smith Contrib Zool 531:243

Kornicker LS (1996) Ostracoda (Myodocopina) from shallow waters of the Northern Territory and Queensland, Australia. Smith Contr Zool 578:97

Kornicker LS (2001) Exopod and protopodial endite III of the maxillae of Sarsiellinae (Crustacea: Ostracoda: Myodocopa). Proc Biol Soc Wash 114:680-685

Kornicker LS (2002a) Comparative morphology of the fifth limb (second maxilla) of myodocopid ostracoda. J Crust Biol $22: 798-818$

Kornicker LS (2002b) Orientation of the maxilla of the Sarsiellinae (Ostracoda). J Crust Biol 22:268-278

Kornicker LS, Cohen AC (1978) Dantynae, a new subfamily of Ostracoda (Myodocopina: Sarsiellidae). Proc Bio Soc Wash 91:490-508

Kornicker LS, Thomassin B (1998) Ostracoda (Myodocopina) of Tuléar Reef complex, SW Madagascar. Smith Contrib Zool 595:134

Kornicker LS, Iliffe TM, Harrison-Nelson E (2002) Ostracoda (Myodocopa) from Bahamian Blue Holes. Smith Contrib Zool 616:99
Kornicker LS, Harrison-Nelson E, Coles SL (2007a) Ostracoda (Myodocopina) from $\mathrm{O}^{\prime}$ ahu and French Frigate Shoals, Hawaiian Islands. Bish Mus Bull Zool 8:1-128

Kornicker LS, Iliffe TM, Harrison-Nelson E (2007b) Ostracoda (Myodocopa) from Anchialine Caves and Ocean Blue Holes. Zootaxa 1565:1-151

Lefébure T, Douady CJ, Gouy M, Gilbert J (2006) Relationship between morphological taxonomy and molecular diversity within Crustacea: proposal of a molecular threshold to help species delamination. Mol Phylogenet Evol 40:435-447

Meisch C (2007) On the origin of the putative furca of the Ostracoda (Crustacea). Hydrobiologia 585:181-200

Oakley TH (2005) Myodocopa (Crustacea: Ostracoda) as models for evolutionary studies of light and vision: multiple origins of bioluminescence and extreme sexual dimorphism. Hydrobiologia 538:179-192

Oakley TH, Cunningham CW (2002) Molecular phylogenetic evidence for the independent evolutionary origin of an arthropod compound eye. Proc Nat Acad Sci 99:1426-1430

Oakley TH, Wolfe JM, Lindgren AR, Zaharoff AK (2012) Phylotranscriptomics to bring the understudied into the fold: monophyletic ostracoda, fossil placement, and pancrustacean phylogeny. Mol Biol Evol 30:215-233

Roberts CM, McClean CJ, Veron JEN, Hawkins JP, Allen GR, McAllister DE, Mittermeier CG, Schueler FW, Spalding M, Wells F et al (2002) Marine biodiversity hotspots and conservation priorities for tropical reefs. Science 295:1280-1284

Spears T, Abele LG (1997) Crustacean phylogeny inferred from $18 \mathrm{~S}$ rDNA. In: Fortey RA, Thomas RH (eds) Arthropod relationships. Syst Assoc Special 55:169-187

Stock JH, Von Vaupel Klein JC (1996) Mounting media revisited: the suitability of Reyne's fluid for small crustaceans. Crustaceana 69:794-798

Tamura K, Peterson D, Peterson N, Stecher G, Nei M, Kumar S (2011) MEGA5: molecular evolutionary genetics analysis using maximum likelihood, evolutionary distance, and maximum parsimony methods. Mol Biol Evol 28:2731-2739

Thompson JD, Higgins DG, Gibson TJ (1994) Clustal-W - improving the sensitivity of progressive multiple sequence alignment through sequence weighting, position-specific gap penalties and weight matrix choice. Nucleic Acids Res 22:4673-4680

Yamaguchi S, Endo K (2003) Molecular phylogeny of Ostracoda (Crustacea) inferred from $18 \mathrm{~S}$ ribosomal DNA sequences: implication for its origin and diversification. Mar Biol 143:23-38 